ISSN 2236-0859

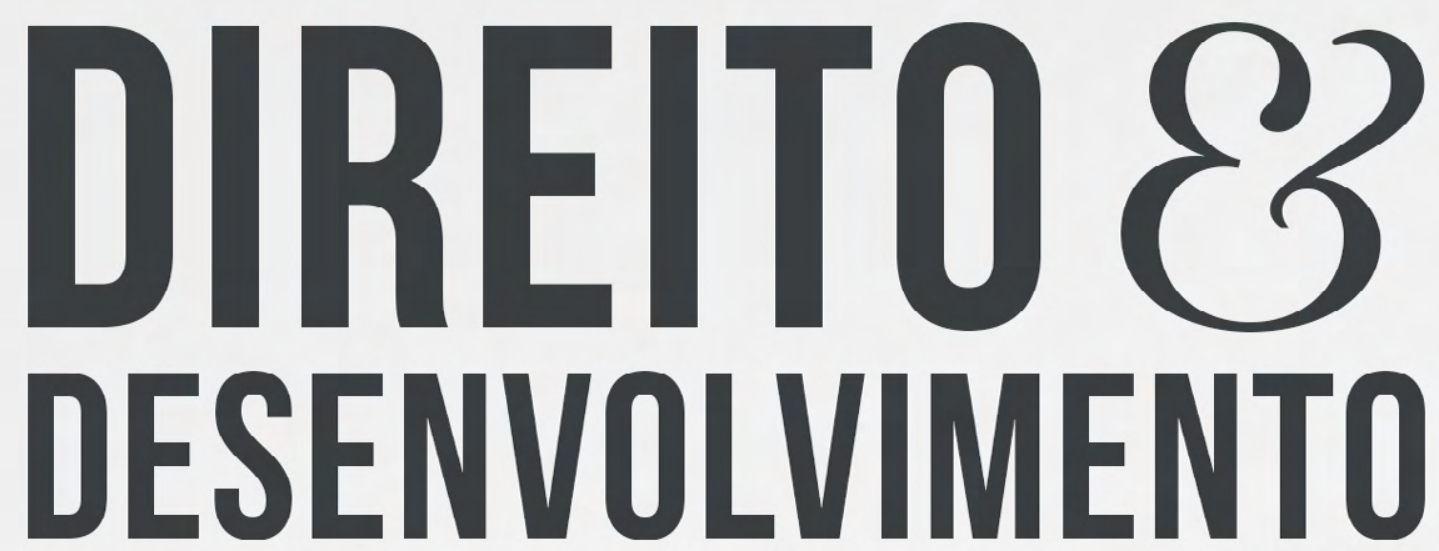

REVISTA DO PROGRAMA DE PÓS-GRADUAÇ̃̃O EM DIREITO MESTRADO EM DIREITO E DESENVOLVIMENTO SUSTENTÁVEL

\title{
"FAKE NEWS" COMO ATIVIDADE CRIADORA DE CONDICÕES ADVERSAS ÀS ATIVIDADES SOCIAISE ECONÔMICAS E SEU ENQUADRAMENTO JURIIIICO NO ÂMBITO DO MEIO AMBIENTE DIGITAL
}

CELSO ANTÔNIO PACHECO FIORILLO

RENATA MARQUUES FERREIRA 


\title{
"FAKE NEWS" COMO ATIVIDADE CRIADORA DE CONDIÇÕES ADVERSAS ÀS ATIVIDADES SOCIAIS E ECONÔMICAS E SEU ENQUADRAMENTO JURÍDICO NO ÂMBITO DO MEIO AMBIENTE DIGITAL
}

\author{
"FAKE NEWS" AS AN ACTIVITY THAT CREATES ADVERSE \\ CONDITIONS FOR SOCIAL AND ECONOMIC ACTIVITIES \\ AND ITS LEGAL FRAMEWORK WITHIN THE DIGITAL \\ ENVIRONMENT
}

Recebido: $11 / 07 / 2018$

Aprovado: 17/09/2018
Celso Antônio Pacheco Fiorillo* Renata Marques Ferreira**

RESUMO: Difundida no âmbito do meio ambiente digital como atividade humana que consiste na veiculação de notícias falsas através de diferentes formas, processos ou veículos "inerente a um modelo de negócios assentado no princípio de que a notícia não custa nada" assim como fundamentada na concepção de que "a veiculação de notícias falsas dá dinheiro", a desinformação ("fake news") acaba por criar condições adversas às atividades sociais e econômicas resguardadas em nosso Estado democrático de direito. Enquadrada no plano normativo como atividade e mais especificamente no plano da sociedade da informação em face da tutela jurídica do meio ambiente digital como atividade poluidora, a desinformação ("fake news") recebe seu necessário enfrentamento jurídico no plano constitucional e infraconstitucional em face do que determina

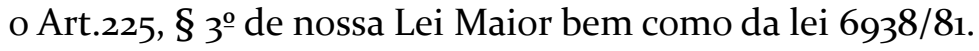

Palavras-Chave: Fake news. Meio ambiente digital. Sociedade da informação. Atividade poluidora. Bens ambientais.

ABSTRACT: Disseminated in the scope of the digital environment as a human activity consisting of the transmission of false news through different forms, processes or vehicles "inherent in a business model based on the principle that the news costs nothing" as well as based on the conception that "Fake news gives money," misinformation ("fake news") ends up creating conditions that are adverse to social and economic activities in our democratic rule of law. Within the normative level as an activity and more specifically in the sphere of the information society in the face of the legal protection of the digital environment as a polluting activity, disinformation ("fake news") receives its necessary legal confrontation in the constitutional and infraconstitutional plan in the face of what determines the Art.225, § 3 of our Major Law as well as of the law $6938 / 81$.

\footnotetext{
*Livre-Docente em Direito Ambiental do Brasil. Doutore Mestre em Direito das Relaçóes Sociais. Professorvisitante da Escola Superior de Tecnologia do Instituto Politécnico de Tomar (PORTUGAL) e Professor Visitante/Pesquisador da Facoltà di Giurisprudenza della Seconda Università Degli Studi di Napoli(ITALIA). Coordenador Científico do periódico Direito Ambiental Contemporâneo/Editora. Saraiva e membro convidado do Conselho Editorial da Revista Aranzadi de Derecho Ambiental(ESPANHA). Professor Permanente do Programa de Mestrado em Direito da UNINOVE-SP. E-mail: celsofiorillo@uol.com.br

**Pós-Doutora pela Universidade de São Paulo (Escola Politécnica-USP). Doutora em Direito das Relações Sociais (sub área de Direitos Difusos e Coletivos-Direito Ambiental) pela Pontifícia Universidade Católica de São Paulo. Mestre em Direito das Relações Sociais (sub área de Direitos Difusos e Coletivos-Direito Ambiental Tributário) pela Pontifícia Universidade Católica de São Paulo. Professora da Escola Superior de Advocacia da Ordem dos Advogados do Brasil - Seção de São Paulo (ESA-OAB/SP). Coordenadora do curso de Direito das Faculdades Integradas Rio Branco - Unidade Granja Viana. Professora das Faculdades Integradas Rio Branco (Fundação Rotary). Coordenadora Científica do periódico Direito Ambiental Contemporâneo/Editora Saraiva. E-mail: renferreira@ uol.com.br
} 
Keywords: Fake news. Digital environment. Information society. Polluting activity. Environmental assets.

\section{INTRODUÇÃO}

Conforme a doutrina pátria especializada na análise das relações jurídicas vinculadas à sociedade da informação vem desenvolvendo, a Constituição da República Federativa do Brasil assegura a todos o acesso à informação como direito individual bem como direito coletivo (Art. $5^{\circ}$, XIV) determinando ainda nossa Lei Maior em seu art. 220 que, sob qualquer forma, processo ou veículo, a informação não sofrerá qualquer restrição, observado o disposto na própria Carta Magna. Além disso, estabelece nosso superior ordenamento normativo que nenhuma lei conterá dispositivo que possa constituir embaraço à plena liberdade de informação jornalística em qualquer veículo de comunicação social, observado o disposto no art. $5^{\circ}$, IV, V, X, XIII e XIV (Art. 220, § $1^{\mathrm{o}}$ ).

Assim nenhuma dúvida existe no sentido de se reconhecer a informação como direito fundamental constitucional assegurado a brasileiros e estrangeiros residentes no País (Art. $5^{\circ}$ da CF), ou seja, como coisa (materialidade da informação), como processo (interação entre registros, o meio e o homem) e como conhecimento (atividades cognitivas de um ser consciente)" ·, ou seja, como bem material ou imaterial que tem valor econômico, servindo de objeto a uma relação jurídica informação prevista no plano normativo como bem cultural de natureza jurídica ambiental, é o fundamento estruturante de nossa atual sociedade da informação em face do denominado meio ambiente digital.

Destarte, a contrario sensu, a desinformação difundida no âmbito do meio ambiente digital como atividade humana que consiste na veiculação de notícias falsas ("fake news") através de diferentes formas, processos ou veículos "inerente a um modelo de negócios assentado no princípio de que a notícia não custa nada" assim como fundamentada na concepção de que "a veiculação de notícias falsas dá dinheiro, conforme indica (MAGNOLI, 2018), acaba por criar condições adversas às atividades sociais e econômicas resguardadas em nosso Estado democrático de direito merecendo adequado enfrentamento jurídico.

Cabe, pois analisar o tema de forma sistemática visando estabelecer em que medida as denominadas "fake news", como atividades desenvolvidas pela pessoa humana com o uso da desinformação, são juridicamente enquadradas no âmbito de nossa Lei Maior assim como, particularmente, em face da lei 6938/81.

\section{O QUE É INFORMAÇÃO. CONCEITO DE INFORMAÇÃO NA DENOMINADA SOCIEDADE DA INFORMAÇÃO EM FACE DO MEIO AMBIENTE DIGITAL}

Ao desenvolver satisfatório estudo sobre o conceito de informação, (MESSIAS, 2005) elaborou pesquisa no âmbito da área de Ciência da Informação apoiada principalmente em reflexões produzidas por" pesquisadores da área, na tentativa de mapear as concepções predominantes para a informação.

Para viabilizar o processo de análise dos resultados restringiu-se apenas a três categorias básicas: informação como coisa (materialidade da informação), como processo (interação entre registros, o meio e o homem) e como conhecimento (atividades cognitivas de um ser consciente). 
[...] obviamente as reflexões enfatizavam uma ou outra concepção, sendo este o principal foco da pesquisa. Vale ressaltar que a grande maioria dos discursos evocava uma abordagem depende de outra, sendo poucos os que se restringiam a apenas uma categoria. Sendo assim, foi possível classificar os conceitos em duas categorias simultâneas, mas poucos foram os artigos que apontavam para as três categorias. $\mathrm{Na}$ análise geral apenas uma das categorias recebeu a maior número de indicações. (MESSIAS, 2005).

"A noção que prevaleceu sobre as demais", conclui a pesquisadora "foi a de informação enquanto coisa, reforçando a objetividade da informação em contraposição a sua subjetividade"

Assim, influenciadas pelas transformações de pensamento e conduta da Sociedade da Informação podemos entender juridicamente o conceito de informação como coisa, ou seja, como um "bem material ou imaterial que tem valor econômico, servindo de objeto a uma relação jurídica” conforme ensina (DINIZ,2018).

Destarte o conceito jurídico de informação como bem material ou imaterial que tem valor econômico, servindo de objeto a uma relação jurídica albergado na atual Sociedade da Informação guardando, pois, conforme destacam Fiorillo/Ferreira·, necessária compatibilidade, "com os deveres e direitos coletivos indicados em nossa Constituição Federal (Art.5ํㅜ e segs.) e especificamente com os denominados interesses difusos e coletivos (art. 129, III, da CF)" assim como com os demais dispositivos citados na Introdução do presente trabalho, guarda absoluta compatibilidade normativa com os bens culturais devendo, pois receber interpretação jurídica em face de sua natureza jurídica de bem ambiental no âmbito do denominado meio ambiente digital.

Cuida-se de observar a relação jurídica ambiental possuindo características peculiares que a definem como multilateral, por envolver sujeitos diversos, tanto públicos como privados. Essa multiplicidade de atores sociais, aliada à conhecida complexidade das questões ambientais contemporâneas, exige o reconhecimento de que o campo de estudos do direito ambiental envolve forte interdisciplinaridade, metodologia esta que busca a união de diferentes disciplinas para tratar de um tema comum aproximando o denominado "direito eletrônico" (ou informático, segundo alguns autores) e o direito ambiental no sentido de evidenciar duas grandes características da chamada "contemporaneidade": a intensidade das trocas sociais que ocorrem por meio das redes informacionais e a busca de patamares de desenvolvimento capazes de produzir menor impacto ambiental.

O século XXI caracteriza-se pelo que se define como "sociedade da informação", em que as tecnologias da comunicação fornecem a base material para a integração global e favorecem o intercâmbio cada vez mais veloz de informações entre indivíduos, corporações e instituições. Apesar das contradições e desigualdades que se fazem presentes neste contexto, a sociedade da informação caracteriza nova forma de produção de relações sociais, baseada na flexibilidade e no incentivo à capacidade criacional. Esse campo de pesquisa possui a mesma complexidade das reflexões ambientais, porque ambos necessitam da compreensão de múltiplas variáveis de tipo econômico, histórico e cultural, para melhor compreender a inter-relação global/local.

A intensidade desses dois campos de produção social deve ser examinada pelo Direito, especialmente a fim de garantir a manutenção das diferenças no Estado Democrático de Direito. Assim, a concepção de um meio ambiente cultural (arts. 215 e 216 da CF) é o espaço propício para analisar as criações tecnológicas informacionais e seu papel nas discussões contemporâneas acerca do desenvolvimento sustentável, unindo assim a preocupação ambiental no contexto da realidade atual.

Para tanto, utiliza-se a concepção da ordem jurídica como um sistema aberto, que traz em seu bojo uma série de regras conformadas pela legalidade constitucional. Ressalte-se que essa legalidade é, antes de tudo, composta por um conjunto de princípios e valores que 
permite mobilidade ao sistema. A ordem constitucional brasileira, por coordenar-se pelo valor da dignidade humana, busca defender a qualidade de vida. O direito fundamental ao meio ambiente ecologicamente equilibrado é elemento importante para obtenção de padrões de vida digna e saudável, no que autoriza a superação da oposição entre objetivos econômicos e estratégias de conservação da natureza, estimulando a busca de padrões sustentáveis de desenvolvimento.

Passemos então a uma breve análise dos bens culturais e sua natureza jurídica de bem ambiental.

\section{A INFORMAÇÃO COMO BEM CULTURAL EM FACE DO MEIO AMBIENTE DIGITAL E SUA NATUREZA JURÍDICA DE BEM AMBIENTAL}

Entendida, conforme argumentos indicados anteriormente, como um bem material ou imaterial que tem valor econômico e servindo de objeto a uma relação jurídica, a informação, ao se encontrar claramente associada às formas de expressão bem como modos de criar, fazer e viver da pessoa humana, é balizada no plano constitucional, na interpretação de (FIORILLO, 2014), como bem cultural associado à comunicação social, apresentando natureza jurídica de bem ambiental em face do denominado meio ambiente digital.

Como destaca referido autor, no âmbito das obras já mencionadas , "o verbo medieval "enforme, informe", emprestado do francês, conforme explicam Briggs e Burke, "significava dar forma ou modelar", e a nova expressão "sociedade da informação" dava forma ou modelava um conjunto de aspectos relacionados à comunicação - conhecimento, notícias, literatura, entretenimento - todos permutados entre mídias e elementos de mídias diferentes: papel, tinta, telas, pinturas, celuloide, cinema, rádio, televisão e computadores".

Assim, observada como bem ambiental de índole cultural, a informação, a partir do que foi estabelecido por nossa Carta Magna de 1988, passa a adotar estrutura normativa própria traduzindo a evolução doutrinária organizadora dos bens culturais como bens ambientais no âmbito do denominado meio ambiente digital e passando a merecer sua defesa em face dos princípios constitucionais do direito ambiental dentro da conhecida e paradigmática interpretação firmada pelo Supremo Tribunal Federal (ADI 3540) em harmonia com o desenvolvimento doutrinário desenvolvido pela doutrina pátria especializada.

Destarte qualquer conduta e atividade considerada juridicamente lesiva à informação, como é evidentemente a distribuição de desinformação destinada a enganar, a fim de obter ganhos os mais variados (financeiros e políticos dentre outros), sujeitará os infratores, pessoas físicas ou jurídicas, a sanções penais e administrativas, independentemente da obrigação de reparar os danos causados em conformidade com o que determina o Art. 225, parágrafo $3^{\text {o }}$ de nossa Carta Magna.

\section{INFORMAÇÃO X DESINFORMAÇÃO: A DESINFORMAÇÃO COMO ATIVIDADE HUMANA VEICULADORA DE NOTICIAS FALSAS ("FAKE NEWS")}

Não tendo qualquer base na realidade, mas apresentadas como sendo factualmente corretas, na apropriada interpretação de Hunt Allcott e Matthew Gentzkow, as notícias falsas ("fake news") e sua veiculação sempre existiram na história como informa Robert Darnton. 
No Brasil, de acordo com levantamento do Grupo de Pesquisa em Políticas Públicas para o Acesso à Informação (Gpopai) da Universidade de São Paulo (USP), cerca de 12 milhões de pessoas difundem notícias falsas sobre política.

Destarte, a desinformação como atividade motivada por razões de natureza econômica ou mesmo social que vêm sendo usada de forma sistemática no século XXI, particularmente no âmbito do meio ambiente digital, passou a ter importância destacada em face de seus evidentes reflexos perniciosos para os Estados democráticos de direito.

Trata se de constatar, conforme advertência de Allcott e Gentzkow, que motivações de natureza pecuniária ou mesmo ideológica, passaram a conduzir uma estratégia intencional destinada a criar condições adversas às sociedades contemporâneas através da produção e difusão, por todas as formas e meios tecnologicamente possíveis, de noticiais falsas desestruturando a ordem social e econômica assegurada juridicamente pelos sistemas normativos constitucionais.

De acordo com um estudo realizado pela London School of Economics (LSE), noticiado pela empresa de comunicação internacional da Alemanha Deutsche Welle (DW), uma forma relativamente nova de publicidade online é o combustível que mantém a máquina de notícias falsas funcionando financeiramente - ou que até mesmo a coloca em funcionamento.

Assim, conforme indica referida matéria graças à receita de publicidade, o incentivo financeiro para a criação e difusão de notícias falsas ainda é alto - apesar da ação maciça do Google para que a indústria de publicidade digital tente conter a avalanche de notícias falsa.

Todavia, adverte a referida matéria,"um estudo conduzido pelo portal de notícias BuzzFeed chegou à conclusão de que, no início de abril, mais de 60 sites que publicam informações falsas ganharam dinheiro com o serviço de publicidade Google AdSense e outras importantes redes de anúncios. Disseminadores de boatos expulsos de certas redes de anúncios muitas vezes, além disso, simplesmente se mudam para outras redes"

\section{INFORMAÇÃO X DESINFORMAÇÃO: DESINFORMAÇÃO COMO ATIVIDADE HUMANA DESTINADA A VEICULAR NOTICIAS FALSAS (“FAKE NEWS”) E SEU ENQUADRAMENTO NORMATIVO NO ÂMBITO DAS ATIVIDADES SOCIAIS E ECONÔMICAS}

Como atividade motivada por razões de natureza pecuniária ou mesmo ideológica, ou seja, por razões de natureza econômica e social, as "fake news" como desinformação que não tem preliminarmente enquadramento jurídico constitucional estabelecido em nossa Carta Magna como umas das possíveis formas de agir que podem ser realizadas pela pessoa humana caracterizando-se, pois, preliminarmente, como um "fenômeno" essencialmente humano.

No plano dos princípios fundamentais de nossa Constituição Federal, a atividade está diretamente associada ao que estabelece o Art. $1^{\circ}$, III, ou seja, como fenômeno humano que é a atividade, para ser adequadamente interpretada no plano maior normativo, deve obedecer ao fundamento constitucional que assegura a dignidade da pessoa humana como regra matriz destinada ao entendimento de seu conteúdo para todos os efeitos e em face de todas as circunstancias em que referido substantivo feminino aparece em nossa Constituição Federal.

A atividade, portanto, no plano jurídico constitucional, não pode ser desenvolvida em detrimento da dignidade da pessoa humana.

Todavia o fato da atividade estar associada diretamente ao que estabelece o Art.1 ${ }^{\circ}$, III da Carta Magna não exclui evidentemente a necessidade de se interpretar o conteúdo da palavra obedecendo também o que estabelecem os demais incisos do Art.1으, igualmente princípios 
fundamentais relacionados às ações humanas e igualmente estabelecidos na Lei Maior como fundamentos interpretativos de nossa República Federativa e suas normas jurídicas.

Assim a soberania, a cidadania, os valores sociais do trabalho e da livre iniciativa bem como o pluralismo político, entendidos em consonância com a dignidade da pessoa humana conforme explica Celso Fiorillo ${ }^{2}$, estruturam juridicamente todas as atividades previstas em nossa Carta Magna e evidentemente as atividades de informação, em decorrência de diferentes circunstancias que terão diferentes consequências normativas (Art. $1^{\circ}$, incisos I, II, IV e V).

Trata-se, pois de verificar, no plano maior constitucional, que a atividade é efetivamente um fenômeno essencialmente humano disciplinado em nossa Constituição Federal; a pessoa humana ao agir de forma direta ou indireta, de forma individual ou coletiva, acaba por gerar diferentes consequências que dependendo da circunstancia ou mesmo enquadramento normativo encontrarão de qualquer forma seu devido amparo constitucional 3 .

De qualquer forma, são várias as oportunidades em que encontramos a palavra atividade explicitamente indicada em nossa Constituição Federal destacando-se aqueles relacionadas às atividades sociais e econômicas.

Traduzindo reflexo direto do conteúdo indicado no art.1ํㅗ III da CF, verificamos no âmbito dos direitos sociais que, dentre os direitos dos trabalhadores urbanos e rurais, está assegurado adicional de remuneração para as atividades penosas, insalubres ou perigosas (Art. $7^{\circ}$, XXIII) sendo certo que em matéria disciplinadora do regime jurídico constitucional dos servidores públicos os titulares de cargos efetivos da União, dos Estados, do Distrito Federal e dos Municípios, incluídas suas autarquias e fundações, que exerçam atividades de risco bem como cujas atividades sejam exercidas sob condições especiais que prejudiquem sua saúde ou sua integridade física, têm regra específica de tutela no que se refere aos requisitos e critérios diferenciados para a concessão de aposentadoria (Art.40, parágrafo $4^{\circ}$, II e III). Também diretamente associado ao art.1 ${ }^{o}$,III-sem prejuízo dos demais incisos do mesmo artigo- determinou a Carta Magna o dever do Estado promover e incentivar o desenvolvimento científico, a pesquisa, a capacitação científica e tecnológica bem como a inovação atividades necessariamente vinculadas à pessoa humana tanto no âmbito individual como metaindividual conforme explicita orientação do Art.218,parágrafo $7^{\circ}$.

Já como reflexo da soberania, da cidadania, dos valores sociais do trabalho e da livre iniciativa assim como do pluralismo político (Art.1 $1^{\circ}$, incisos I,II,IV e V) ) são muitas as hipóteses em que a palavra atividade é indicada no plano da Carta Magna. Alguns exemplos merecem registro, a saber: atividade nociva ao interesse nacional (Art.12, II, § $4^{\circ}$,I), atividade militar(Art. 14. § 8o, I ;Art.143, § 1º ), atividade nuclear(Art.21,XXIII,"a”;Art.22,XXVI;Art.49,XIV), atividade de garimpagem (Art.21,XXV),atividade essencial ao funcionamento do Estado(Art.37,XXII), atividades do Tribunal de Contas(Art.71, § $4^{\circ}$ ), atividades jurídicas(Art.93,I.129, § $3^{\circ}$ ), atividades jurisdicionais(Arts.93,XII;107 § $20 ; 115$, § $1^{\circ}$;125 § $7^{\text {o }}$ ), atividades profissionais(Arts.94;107,I;11A,I;115,I;123,I;Art.8º, § 2º; §5º do ADCT ), atividade político-partidária(Arts.95, § único,III;128, §5º ,II, "e"),atividades específicas da justiça(Art.98, § 2º ),atividade policial(Art.129,VII),atividades do Conselho Nacional do Ministério Público (Art.13o-A, § 2oㅡ, V), atividade de consultoria e assessoramento jurídico do Poder Executivo(Art.131), atividade de defesa civil(Art.144, $§ 5^{\circ}$ ),atividades dos órgãos responsáveis pela segurança pública(Art.144, $§ 7^{\circ}$ ),atividades previstas em lei(Art.144, § 10,I),atividade econômica do contribuinte(Art.145, § 1º ), atividade econômica relacionada a patrimônio, renda e serviços(Art.150, § $3^{\mathbf{0}}$ ), atividade preponderante(Art.156,II, § $2^{-}$), atividades da administração tributária(Art.167,IV),princípios gerais da atividade econômica(

2 FIORILlO, Celso Antonio Pacheco. Princípios constitucionais do direito da sociedade da informação, São Paulo: Saraiva 2014, passim.

3 Vide FIORILLO, Celso Antonio Pacheco; FERREIRA, Renata Marques. Comentários ao Estatuto da Cidade — Lei 10.257/o1 — Lei do Meio Ambiente Artificial. São Paulo: Saraiva, 6a edição, 2014 


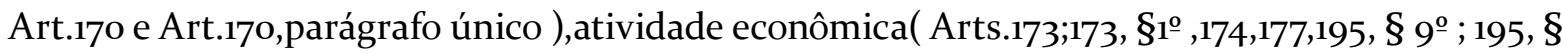
12) ,atividade de importação ou comercialização(Art.177, § $4^{\circ}$ ), atividade em regime de economia familiar(Arts. 195, § 8o; 201, § $7^{\mathbf{0}}$,II),atividades de agente comunitário de saúde e agente de combate às endemias(Art.198, § 50 ), atividade privada para efeito de aposentadoria(Art.201, § $9^{-}$), atividade rural para efeito de aposentadoria(Art.201, § $9^{\circ}$ ), atividade urbana para efeito de aposentadoria(Art.201, § $9^{\circ}$ ),gestão de atividades das empresas jornalísticas e de radiodifusão sonora e de sons e imagens(Art.222, $§ 1^{-}{ }^{-}$), atividades de seleção e direção da programação veiculada pelas empresas jornalísticas e de radiodifusão sonora e de sons e imagens(Art.222, § $2^{-}$), atividade potencialmente causadora de significativa degradação do meio ambiente(Art.225, $\S 1^{\circ}$, inciso IV), atividade considerada lesiva ao meio ambiente(Art.225, $\S 3^{\circ}$ ), atividade produtiva dos índios(Art.231, § $1^{\circ}$ ), atividade notarial(Art.236, § $1^{\circ}$ e $\S 3^{\circ}$ n), atividade exclusiva do Estado(Art.247),permanência em atividade para efeitos de anistia(Art.8o do ADCT),atividade remunerada(Art.8o, § 20 do ADCT), atividade dos sindicatos rurais(Art.10, $§ 2^{\circ}$ do ADCT) e Ministério Público Federal, Procuradoria-Geral da Fazenda Nacional, Consultorias Jurídicas dos Ministérios, Procuradorias e Departamentos Jurídicos de autarquias federais com representação própria e o membros das Procuradorias das Universidades fundacionais públicas exercendo suas atividades(Art.29 do ADCT) dentre outros.

Destarte, no âmbito constitucional, a palavra atividade como fenômeno essencialmente humano está evidentemente relacionada à faculdade ou possibilidade de agir, de se mover, de fazer, empreender coisas em face de diferentes circunstancias todas elas relacionadas ao que determinam os princípios fundamentais da Carta Magna; como dissemos a pessoa humana ao agir de forma direta ou indireta, de forma individual ou coletiva, acaba por gerar diferentes consequências que dependendo da circunstancia ou mesmo enquadramento normativo encontrarão de qualquer forma seu devido amparo constitucional ${ }^{4}$.

\section{INFORMAÇÃO X DESINFORMAÇÃO: A DESINFORMAÇÃO COMO ATIVIDADE DESTINADA A VEICULAR NOTICIAS FALSAS ("FAKE NEWS") E SEU ENQUADRAMENTO NORMATIVO NO ÂMBITO DO MEIO AMBIENTE DIGITAL: A CONSTITUIÇÃO FEDERAL E A LEI 6938/81}

Como atividade destinada a veicular notícias falsas as "fake news" são consideradas constitucionalmente lesivas ao meio ambiente cultural, conforme argumentos anteriormente desenvolvidos, sujeitando os infratores, pessoas físicas ou jurídicas, a sanções penais e administrativas, independentemente da obrigação de reparar os danos causados tudo em

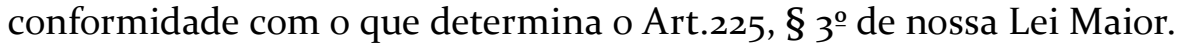

Verifique-se que já sob a égide da lei 6.938/81 nosso sistema normativo já estabelecia, e continua estabelecendo, que a degradação da qualidade ambiental resultante de atividades que direta ou indiretamente criem condições adversas às atividades sociais e econômicas, hipótese claramente associada às atividades de desinformação ("fake news"), são consideradas poluentes (Art. $3^{\circ}$,III,letra b) obrigando o infrator, independentemente da existência de culpa, a indenizar ou reparar os danos causados afetados por sua atividade(Art,14, § 1ㅇ).

De qualquer forma, mais importante que reparar danos (o que na maioria das vezes em nada auxilia uma eficiente resposta em face dos danos efetivamente causados e consumados com a desinformação no âmbito das atividades sociais e econômicas...) admite também nossa legislação medidas destinadas a assegurar o princípio constitucional da prevenção regra fundamental estabelecida pelo direito ambiental constitucional, mas que também devem

4 Com relação à palavra INATIVIDADE vide Art. 14,§ 8o; Art. 142.,X ; Art. 8o do ADCT. 
ser observadas como sendo de duvidosa aplicação prática em face das situações concretas de atividades de desinformação.

Destarte iniciativas recentes realizadas por parlamentos de outros países no sentido de estabelecer normas específicas para o enfrentamento do tema, como a lei alemã aprovada em 30 de junho de 2017 (Netzwerkdurchsetzungsgesetz - NetzDG) além e divulgadas com grande alarde pela mídia, muito pouco ou quase nada acrescentam às repostas normativas já existentes no Brasil.

\section{CONSIDERAÇÕES FINAIS}

Difundida no âmbito do meio ambiente digital como atividade humana que consiste na veiculação de notícias falsas através de diferentes formas, processos ou veículos "inerente a um modelo de negócios assentado no princípio de que a notícia não custa nada assim como fundamentada na concepção de que "a veiculação de notícias falsas dá dinheiro desinformação ("fake news") ao criar condições adversas às atividades sociais e econômicas resguardadas em nosso Estado democrático de direito mereceu por parte de nossa legislação resposta normativa que disciplina a matéria, no âmbito dos princípios constitucionais ambientais que estruturam o meio ambiente digital. Destarte, podendo ser entendia como atividade consideradas constitucionalmente lesiva ao meio ambiente (meio ambiente cultural), a atividade de desinformação ("fake news") sujeita os infratores, pessoas físicas ou jurídicas, a sanções penais e administrativas, independentemente da obrigação de reparar os danos causados

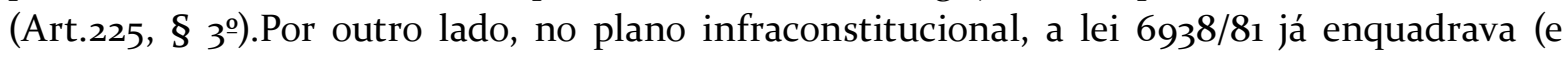
continua enquadrando...) explicitamente a degradação da qualidade ambiental resultante de atividades que direta ou indiretamente criem condições adversas às atividades sociais e econômicas, hipótese claramente associada às atividades de desinformação ("fake news",como sendo poluidora sujeitando os infratores/poluentes , a indenizar ou reparar os danos causados afetados por sua atividade (Art.14, § $1^{\circ}$ ).

Todavia persiste a dúvida se as respostas constitucionais e infraconstitucionais antes indicadas e já existentes seriam suficientes e mesmo satisfatórias no sentido de resguardar o Estado democrático de direito dos efeitos danosos- e muitas vezes irreversível- de uma atividade humana que sempre existiu visando, em prejuízo da maioria da população, auferir vantagens pecuniárias ou mesmo "ganhos" ideológicos através de práticas contrárias à ética e à democracia.

Necessário, pois aprimorar nossa legislação visando estabelecer no plano infraconstitucional o necessário balizamento no sentido de implementar o comando constitucional que responsabiliza criminalmente os infratores, pessoas físicas ou jurídicas, a sanções penais em face de atividades destinadas a veicular notícias falsas ("fake news").

\section{REFERÊNCIAS}

ALONSO, D. V. Lenguaje e información. Data Grama Zero - Revista de Ciência da Informação, Rio de Janeiro, v. 2, n. 4, ago. 2001. Disponível em: <http://www.dzg.org.br/ agoo1/f_I_art.htm.> Acesso em: 05 jan.2018.

ARDIZZONE, Antonella. Copyright digitale - 1 'impatto delle nuove tecnologie tra economia e Diritto.G. Giappichelli Editore, 2009. 
BUCKLAND, M. Information as thing. Journal of the American Society of Information Science, v. 42, n. 5, p. 351-36o, jun. 1991. Disponível em: <http://www.uff.br/ppgci/editais/ bucklandcomocoisa.pdf.> Acesso em: 20 jan.2018.

CHIMIENTI, Laura. La nuova proprieta' intellettuale nella societa' dell'informazione. La disciplina europea e italiana. Dott. A. Giuffrè Editore S.P.A., 2005.

DINIZ, Maria Helena. Curso de Direito Civil Brasileiro. Direito das Coisas - v. 4, São Paulo: Saraiva, 2018.

FIORILLO, Celso Antonio Pacheco; FERREIRA, Renata Marques. Tutela Jurídica do Whatsapp na Sociedade da Informação. Rio de Janeiro: Lumen Juris, 2017.

. Liberdade de expressão e direito de resposta na Sociedade da Informação, Rio de Janeiro: Lumen Juris, 2017.

. Tutela Jurídica do Patrimônio Genético em face da Sociedade da Informação. Rio de Janeiro: Lumen Juris, 2016.

O Direito de Antena em face do Direito Ambiental no Brasil, São Paulo: Saraiva, 2000 .

O Marco Civil da Internet e o Meio Ambiente Digital na Sociedade da Informação, São Paulo: Saraiva, 2015.

Princípios constitucionais do direito da sociedade da informação, São Paulo: Saraiva, 2014.

Crimes no Meio Ambiente Digital em face da Sociedade da Informação. 2. ed. São Paulo: Ed. Saraiva, 2016.

Curso de Direito Ambiental Brasileiro,18. ed. revista, ampliada e atualizada, Saraiva, 2018.

. Tutela Jurídica do Patrimônio Cultural Brasileiro em face do Direito Ambiental Constitucional. Rio de Janeiro: Lumen Juris, 2018.

GALVÃO, A. P. A. Informação como Commodity: mensurando o setor de informações em uma nova economia. Ciência da Informação, Brasília, v. 28, n. 1, p. 67-71, jan./abr. 1999.

LYOTARD, Jean-François. A condição pós-moderna. São Paulo: José Olympio, 2002.

MAGNOLI, Demétrio Para subverter a lei do Face. Jornal Folha de São Paulo. Ed. de 20 jan. 2018. Disponível em: <http://www1.folha.uol.com.br/colunas/demetriomagnoli/2018/o1/1951949para-subverter-a-lei-do-face.shtml> Acesso em: 20 jan.2018. 
MESSIAS, Lucilene Cordeiro da Silva Messias Informação: um estudo exploratório do seu conceito em periódicos científicos brasileiros da área de Ciência da InformaçãoDissertação (Mestrado) - Faculdade de Filosofia e Ciências - Universidade Estadual Paulista, Marília, 2005.

PINHEIRO, L. V. R. Informação: esse obscuro objeto da ciência da informação, Morpheus Revista Eletrônica em Ciências Humanas: Conhecimento e Sociedade, ano. 2, n. 4, 2004. Disponível em: <http://www.unirio.br/cead/morpheus> Acesso em: 20 jan.2018.

SALVAT, Martinrey; Guiomar, Serrano Marín Vicente. La revolución digital y la Sociedad de la Información. Editorial: Comunicacion Social Ediciones y publicaciones, 2013.

SERRANO, Pascual. Desinformación cómo los medios ocultan el mundo. Editorial: Booket Barcelona. España, 2013.

SERRANO, Pascual. Traficantes de información - La historia oculta de los grupos de comunicación españoles. Editorial: Foca, Ediciones y Distribuciones Madrid. España 2012.

SUAIDEN Neto, Elias. La sociedad de la información en Brasil y España - estudio comparado basado en programas de inclusión digital. Ediciones Trea, S.L., 2011.

ZEMAN, J. Significado filosófico da noção de informação. In: ROYAUMONT, C. de (Org.). O conceito de informação na ciência contemporânea. Rio de Janeiro: Paz e Terra, 1970. p. 154-168. 